\title{
No evidence that established type 2 diabetes susceptibility variants in the PPARG and $K C N J 11$ genes have pleiotropic effects on early growth
}

\author{
A. J. Bennett • U. Sovio • A. Ruokonen • \\ H. Martikainen - A. Pouta • A.-L. Hartikainen • \\ S. Franks • P. Elliott • M.-R. Järvelin • M. I. McCarthy
}

Received: 25 June 2007 / Accepted: 28 September 2007 / Published online: 10 November 2007

(C) Springer-Verlag 2007

\begin{abstract}
Aims/hypothesis The P12A variant in the PPARG gene and the E23K polymorphism in KCNJ11 are both known to influence individual predisposition to type 2 diabetes. If the effect of these variants on insulin secretion and action were to extend to an influence on early growth (which is largely mediated by insulin), it would offer an explanation for observed associations between low birthweight and subsequent diabetes. Since previous studies of the effects of these variants on early growth have been limited and conflicting, we examined these associations in a large, well-characterised birth cohort.

Methods The P12A and E23K variants were genotyped in (respectively) 5,652 and 5,632 individuals from the Northern Finland Birth Cohort of 1966 and we sought associations with early growth phenotypes.
\end{abstract}

Electronic supplementary material The online version of this article (doi:10.1007/s00125-007-0863-1) contains supplementary material, which is available to authorised users.

\section{A. J. Bennett $\cdot$ M. I. McCarthy $(\bowtie)$}

Oxford Centre for Diabetes, Endocrinology \& Metabolism,

University of Oxford,

Oxford OX3 7LJ, UK

e-mail: mark.mccarthy@drl.ox.ac.uk

U. Sovio · P. Elliott $\cdot$ M.-R. Järvelin

Department of Epidemiology and Public Health, Imperial College London,

London, UK

\section{A. Ruokonen \\ Department of Clinical Chemistry, University of Oulu, Oulu, Finland}

H. Martikainen · A. Pouta · A.-L. Hartikainen Department of Obstetrics and Gynecology, University of Oulu, Oulu, Finland
Results Neither variant was associated with birthweight (P12A, $p=0.42$; E23K, $p=0.44$, additive models) or other measures of early growth. Although a previous report had suggested that the P12A effect on adult insulin sensitivity was restricted to small babies, we were unable to reproduce this finding $(p=0.40)$, nor did we confirm a previous report of an association with gestational age $(p=0.23)$.

Conclusions/interpretation Despite a larger sample size than previous studies, we were unable to detect any effect of these variants on early growth. These findings do not support the notion that there are shared genetic determinants of low birthweight and adult diabetes.

Keywords Early growth phenotypes $\cdot$ KCNJ11 - Low birthweight $\cdot$ Metabolic disease $\cdot$ Northern Finland Birth Cohort 1966 - Peroxisomal proliferator-activated receptor gamma Potassium inwardly-rectifying channel, subfamily J, member $11 \cdot P P A R G$. Type 2 diabetes-susceptibility variants

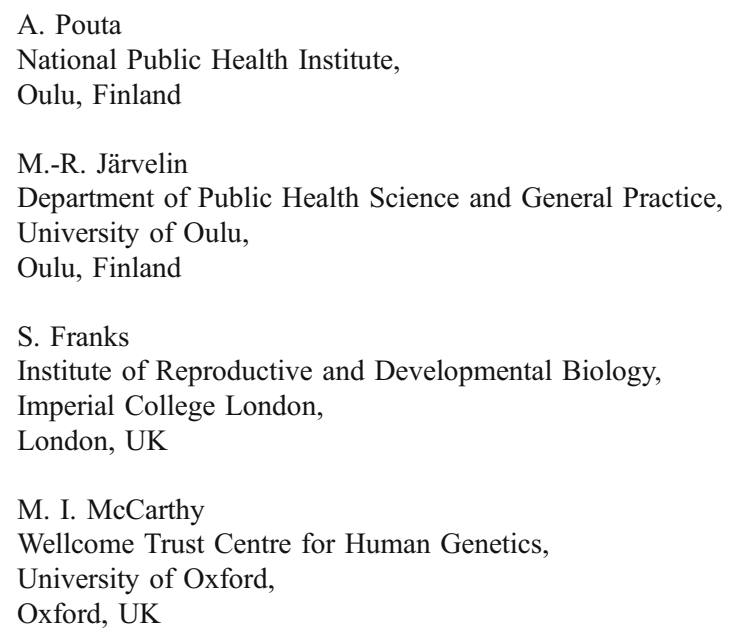




\section{Abbreviations}

HOMA homeostatic model assessment

IR insulin resistance

\section{Introduction}

The well-replicated relationship between restricted early growth and subsequent adult metabolic disease is generally ascribed to the long-term effects of an adverse maternal environment mediated through metabolic programming [1]. However, a complementary explanation of such associations is provided by the hypothesis that early growth and adult metabolic disease share genetic determinants [1]. Support for this latter explanation comes from monogenic forms of diabetes (such as those due to mutations in the $G C K$ gene) and reported associations between paternal metabolic disease and reduced offspring birthweight [2]. However, some twin studies argue against such a shared genetic basis for these traits [3].

One way to test the extent to which common variants with pleiotropic effects impact on observed associations between early growth and adult disease is to establish whether or not variants influencing susceptibility to metabolic conditions such as type 2 diabetes also influence early growth phenotypes. Until the recent advent of genome-wide association scans, common variants showing robust associations with individual susceptibility to type 2 diabetes were limited to just three genes (PPARG, KCNJ11 and TCF7L2) [4].
Data on the effects of these variants on early growth phenotypes are limited and conflicting. Although it is known that rarer, more severe mutations in KCNJ11, which cause neonatal diabetes, result in low birthweight [4], the only study of the common type 2 diabetes-susceptibility variant E23K found no association with birthweight [5]. In the case of PPARG, Eriksson and colleagues found no association between the $\mathrm{P} 12 \mathrm{~A}$ variant and birthweight in individuals from the Helsinki Birth Cohort, but did report an interaction effect, whereby the association between the alanine allele and lower fasting insulin in adulthood was restricted to low birthweight individuals [6]. A recent study suggested that carriers of the alanine allele were more likely to have a lower birthweight due to shorter gestation and, indeed, a higher frequency of alanine carriers was observed in the pre-term group [7]. In contrast, the largest study to date, involving 1,930 women and child pairs, found no association between the P12A variant and indices of early growth [8]. Finally, a large-scale study, which found evidence for higher birthweight amongst infants carrying type 2 diabetes-susceptibility alleles at the TCF7L2 locus, attributed this to an indirect effect mediated by the effects of maternal genotype on glucose levels during the pregnancy [9].

In the present study, we set out to perform a wellpowered analysis of the effects of the established type 2 diabetes-susceptibility variants, P12A and E23K (in PPARG and $K C N J 11$ respectively) on early growth phenotypes, using more than 5,000 individuals from the Northern Finland Birth Cohort of 1966.

Table 1 Association between P12A and E23K genotype and early growth phenotypes

\begin{tabular}{|c|c|c|c|c|c|c|c|}
\hline $\begin{array}{l}\text { Early growth variable } \\
\text { by variant }\end{array}$ & Total $(n)$ & $\begin{array}{l}\text { Number of } \\
\text { rare allele } \\
\text { homozygotes } \\
{[n(\%)]}\end{array}$ & $\begin{array}{l}\text { Mean (SD) of } \\
\text { common allele } \\
\text { homozygotes }\end{array}$ & $\begin{array}{l}\text { Mean (SD) of } \\
\text { heterozygotes }\end{array}$ & $\begin{array}{l}\text { Mean }(\mathrm{SD}) \\
\text { of rare allele } \\
\text { homozygotes }\end{array}$ & $\begin{array}{l}p \text { value } \\
\text { unadjusted } \\
\text { additive model }\end{array}$ & $\begin{array}{l}p \text { value } \\
\text { adjusted } \\
\text { additive model }\end{array}$ \\
\hline \multicolumn{8}{|l|}{$P P A R G$ P12A } \\
\hline Birthweight (g) & 5,541 & $179(3.2)$ & $3,494(534)$ & $3,495(505)$ & $3,511(458)$ & 0.77 & 0.42 \\
\hline Birth length $(\mathrm{cm})$ & 5,494 & $176(3.2)$ & $50(2)$ & $50(2)$ & $50(2)$ & 0.70 & 0.91 \\
\hline $\begin{array}{l}\text { Ponderal index } \\
{\left[100 \times\left(\mathrm{g} / \mathrm{cm}^{3}\right)\right]}\end{array}$ & 5,494 & $176(3.2)$ & $2.74(0.25)$ & $2.73(0.27)$ & $2.73(0.24)$ & 0.98 & 0.48 \\
\hline Placenta $(\mathrm{g})$ & 4,805 & $154(3.2)$ & $651(145)$ & $650(144)$ & 649 (149) & 0.88 & 0.72 \\
\hline $\begin{array}{l}\text { Head circumference } \\
\text { at } 1 \text { year }(\mathrm{cm})\end{array}$ & 4,996 & $164(3.3)$ & $47(2)$ & $47(1)$ & $47(1)$ & 0.33 & 0.52 \\
\hline \multicolumn{8}{|l|}{ KCNJ11 E23K } \\
\hline Birthweight (g) & 5,480 & $1,297(23.2)$ & $3,493(518)$ & $3,493(521)$ & $3,493(511)$ & 1.00 & 0.44 \\
\hline Birth length $(\mathrm{cm})$ & 5,433 & $1,288(23.2)$ & $50(2)$ & $50(2)$ & $50(2)$ & 0.89 & 0.93 \\
\hline $\begin{array}{l}\text { Ponderal index } \\
\left(100 \times \mathrm{g} / \mathrm{cm}^{3}\right)\end{array}$ & 5,433 & $1,288(23.2)$ & $2.74(0.24)$ & $2.73(0.26)$ & $2.74(0.25)$ & 0.98 & 0.60 \\
\hline Placenta $(\mathrm{g})$ & 4,749 & $1,120(23.2)$ & $660(144)$ & $646(145)$ & $646(138)$ & 0.01 & 0.03 \\
\hline Head circumference $(\mathrm{cm})$ & 4,935 & $1,164(23.3)$ & $47(1)$ & $47(2)$ & $47(2)$ & 0.64 & 0.93 \\
\hline
\end{tabular}

The mean (SD) is shown for the three genotype groups

Type 2 diabetes risk is associated with the common $(\mathrm{P})$ allele at PPARG and the rarer $(\mathrm{K})$ allele at KCNJ11

a $p$ values adjusted for: sex, gestational week, parity, maternal height and BMI, maternal working during pregnancy, parental socioeconomic status, maternal depression during pregnancy, wantedness of pregnancy, maternal smoking during pregnancy and mother's age 


\section{Methods}

Samples The Northern Finland Birth Cohort of 1966 originally ascertained $96 \%$ of all women in the northernmost two provinces of Finland with expected dates of delivery during 1966 (12,058 live births) [9]. Data were collected on parental environment and pregnancy progress and outcome, including standardised measures of birthweight, birth length and placental weight. Ponderal index was calculated as the ratio of birthweight to birth length cubed. Gestational week was calculated from the date of the last recalled menstruation of the mother, collected via questionnaire between the 24th and 28th gestational week. Follow-up data collected at 12 months of age included head circumference in $90.2 \%$ of cohort members. At 31 years, all cohort members still resident in northern Finland or the Helsinki area $(n=8,463)$ were re-contacted and invited for clinical examination (response rate $71 \%$ ) and DNA sampling (5,753 samples available). The phenotypic characteristics of the cohort sample are shown in the Electronic supplementary materials (ESM) Table 1 . The subset with DNA is representative of the original cohort in terms of birth and early growth phenotypes. Homeostatic model assessment (HOMA) measures of insulin resistance (HOMA-IR) were calculated from the measures of fasting insulin and glucose using the HOMA2 calculator (http:// www.dtu.ox.ac.uk/homa). All individuals gave fully informed consent and the study was approved by ethics committees in Oulu and Oxford and in accordance with the Declaration of Helsinki.

Genotyping Genotyping was performed by KBioscience (Hoddesdon, UK; http://www.kbioscience.co.uk) using
Taqman assays (Applied Biosciences, Warrington, UK). The P12A and E23K variants were successfully genotyped in 5,652 and 5,632 samples (respectively) with estimated error rates $<0.5 \%$ for both ( $\sim 400$ duplicate genotypes). Allele frequencies at both sites (P12, 83\%; E23, 52.3\%) were consistent with those previously reported in Finns; there were no departures from Hardy-Weinberg equilibrium $(p=0.39$ and 0.59 respectively).

Statistical analyses Statistical analyses were performed using SPSS (version 14; SPSS, Chicago, IL, USA). Linear regression was used to investigate potential associations between genotypes and phenotypes of interest (after transformation to normality, where appropriate). We excluded twins from all analyses. In addition, participants with non-fasted samples $(n=229)$ and those on diabetes medication $(n=30)$ were excluded from analyses of insulin and HOMA-IR. Early growth analyses were optionally adjusted for a suite of variables (Table 1), which, within the Northern Finland Birth Cohort of 1966 sample, display univariate associations: we report only the additive model. For analyses seeking to replicate the specific findings of previous studies $[6,7]$, we reproduce the genotypic and phenotypic stratifications reported in those studies.

Power calculations Assuming a power of $80 \%$, an alphavalue of 0.05 and an additive model, this study would have the power to detect a per-allele difference of $8 \%(\sim 43 \mathrm{~g}$ for birthweight) or $6 \%$ ( $32 \mathrm{~g}$ for birthweight) of a standard deviation for $\mathrm{P} 12 \mathrm{~A}$ and $\mathrm{E} 23 \mathrm{~K}$ respectively. This power is similar to studies in this cohort of the glucokinase $-30 \mathrm{G} / \mathrm{A}$ variant $(8.5 \%, \sim 46 \mathrm{~g}$ for birthweight) or TCF7L2 rs7903146 (7\%, $38 \mathrm{~g}$ for birthweight) [9].

Table 2 Relationship between P12A genotype and measures of adult insulin sensitivity, stratified by birthweight

\begin{tabular}{|c|c|c|c|c|c|c|}
\hline \multicolumn{7}{|l|}{ Birthweight group } \\
\hline $\begin{array}{l}\text { Genotype groups by measure of } \\
\text { insulin sensitivity }\end{array}$ & $n$ & $\begin{array}{l}<3,000 \text { g geometric } \\
\text { mean }(\mathrm{SD} \text { range) }\end{array}$ & $n$ & $\begin{array}{l}3,000-3,500 \mathrm{~g} \text { geometric } \\
\text { mean (SD range) }\end{array}$ & $n$ & $\begin{array}{l}>3,500 \mathrm{~g} \text { geometric } \\
\text { mean }(\mathrm{SD} \text { range) }\end{array}$ \\
\hline \multicolumn{7}{|l|}{ Fasting insulin $(\mathrm{pmol} / \mathrm{l})^{\mathrm{a}}$} \\
\hline $\mathrm{P} 12 \mathrm{P}$ & 650 & $56.9(37.5-85.4)$ & 1,258 & $56.9(37.5-85.4)$ & 1,837 & $53.5(36.8-78.5)$ \\
\hline $\mathrm{P} 12 \mathrm{~A}$ A12A & 255 & $56.3(38.2-83.3)$ & 624 & $54.9(36.8-82.6)$ & 836 & $52.8(36.8-75.0)$ \\
\hline Unadjusted $p$ value & & 0.53 & & 0.09 & & 0.24 \\
\hline Adjusted $p$ value ${ }^{\mathrm{b}}$ & & 0.40 & & 0.20 & & 0.25 \\
\hline \multicolumn{7}{|l|}{ HOMA-IR } \\
\hline $\mathrm{P} 12 \mathrm{P}$ & 559 & $1.0(0.7-1.5)$ & 1,191 & $1.0(0.7-1.5)$ & 1,744 & $1.0(0.7-1.4)$ \\
\hline P12A A12A & 226 & $1.0(0.7-1.5)$ & 584 & $1.0(0.7-1.5)$ & 797 & $1.0(0.7-1.4)$ \\
\hline Unadjusted $p$ value & & 0.71 & & 0.09 & & 0.29 \\
\hline Adjusted $p$ value ${ }^{\mathrm{b}}$ & & 0.90 & & 0.18 & & 0.14 \\
\hline
\end{tabular}

Analyses recapitulate those in the previous report [6]

Analyses were by linear regression

${ }^{\mathrm{a}}$ To convert to $\mathrm{mU} / 1$, divide values by 6.945

${ }^{\mathrm{b}} p$ value adjusted for sex and BMI 


\section{Results}

The main findings with respect to the associations between the $\mathrm{P} 12 \mathrm{~A}$ and E23K variants and early growth phenotypes are shown in Table 1 . Neither variant was significantly associated with birthweight, birth length, ponderal index or head circumference at 1 year. In addition, no associations were observed after stratification for parity or sex (data not shown). There was a nominally significant association between the E23 allele and placental weight ( $p=0.026$ adjusted).

To test the previously reported interaction between P12A and birthweight [6], we divided birthweight into the same categories as the original report. We observed the expected association between low birthweight and raised adult measures of fasting insulin $\left(p=2.5 \times 10^{-5}\right)$ and HOMA-IR $\left(p=3.3 \times 10^{-5}\right)$. However, in contrast to the previous report [6], we found no evidence that the P12A genotype had any impact on either variable in low-birthweight individuals (Table 2). Neither was the A allele found to associate with low birthweight due to short gestation $(p=0.81)$ or with preterm birth itself $(p=0.66)$ as previously reported (data not shown) [7].

\section{Discussion}

In this, the largest and most comprehensive study to date of the relationship between these established type 2 diabetessusceptibility variants and early growth, we did not find any evidence of shared pleiotropic effects. Such a finding would be consistent with the largest studies previously performed at each variant $[5,8]$.

What might underlie these discrepant findings? Extensive genotyping quality control and standardised phenotyping have minimised the risk of technical errors affecting our study. In addition, we have previously demonstrated that this sample is able to detect other well-established genotypephenotype correlations $[9,10]$. Overall, the most likely conclusion is that these two variants have little or no effect on early growth phenotypes, a finding which would be consistent with the previous large-scale studies [5, 8].

However, we acknowledge that in this, as in any association study, failure to detect associations may reflect inadequate power to detect small effects [9]. The present study, although large, is also limited by the fact that maternal DNA samples were not available. In principle, any direct effects of susceptibility alleles in the offspring that lead to reduced birthweight (for example through reduced fetal insulin secretion) may be (partly or completely) offset by an opposing effect on early growth mediated through the effects of the same variants on maternal glucose levels [9].
A full exploration of such effects is restricted to data sets featuring both fetal and maternal DNA samples.

In summary, our study failed to detect any significant associations between the $\mathrm{E} 23 \mathrm{~K}$ and $\mathrm{P} 12 \mathrm{~A}$ variants and a range of early growth phenotypes. This provides important evidence that there is limited overlap between susceptibility to type 2 diabetes and influences on early growth phenotypes, arguing against the notion of shared genetic determinants of both [1]. The recent identification, using genome-wide association approaches, of a number of further type 2 diabetessusceptibility variants provides the opportunity for additional tests of this hypothesis.

Acknowledgements This work was supported by the Academy of Finland and the Wellcome Trust (Project Grant GR069224). We thank L. Peltonen-Palotie and O. Törnwall (Helsinki) for their assistance with DNA quantification and distribution. We are grateful to the many patients, relatives, nurses and physicians who contributed to this cohort.

Duality of interest The authors declare that there is no duality of interest associated with this manuscript.

\section{References}

1. Hattersley AT, Tooke JE (1999) The fetal insulin hypothesis: an alternative explanation of the association of low birthweight with diabetes and vascular disease. Lancet 353:1789-1792

2. Wannamethee SG, Lawlor DA, Whincup PH, Walker M, Ebrahim S, Davey-Smith G (2004) Birthweight of offspring and paternal insulin resistance and paternal diabetes in late adulthood: cross sectional survey. Diabetologia 47:12-18

3. Poulsen P, Vaag AA, Kyvik KO, Moller JD, Beck-Nielsen H (1997) Low birth weight is associated with NIDDM in discordant monozygotic and dizygotic twin pairs. Diabetologia 40:439-446

4. Owen KR, McCarthy MI (2007) Genetics of type 2 diabetes. Curr Opin Genet Dev 17:239-244

5. Weedon MN, Gloyn AL, Frayling TM, Hattersley AT, Davey SG, Ben-Shlomo Y (2003) Quantitative traits associated with the type 2 diabetes susceptibility allele in Kir6.2. Diabetologia 46:10211023

6. Eriksson JG, Lindi V, Uusitupa M et al (2002) The effects of the Pro12Ala polymorphism of the peroxisome proliferator-activated receptor-gamma2 gene on insulin sensitivity and insulin metabolism interact with size at birth. Diabetes 51:2321-2324

7. Meirhaeghe A, Boreham CA, Murray LJ et al (2007) A possible role for the PPARG Pro12Ala polymorphism in preterm birth. Diabetes 56:494-498

8. Pfab T, Poralla C, Richter CM et al (2006) Fetal and maternal peroxisome proliferator-activated receptor gamma2 Pro12Ala does not influence birth weight. Obesity (Silver Spring) 14: $1880-1885$

9. Freathy RM, Weedon MN, Bennett A et al (2007) Type 2 diabetes TCF7L2 Risk genotypes alter birth weight: a study of 24,053 individuals. Am J Hum Genet 80:1150-1161

10. Frayling TM, Timpson NJ, Weedon MN et al (2007) A common variant in the FTO gene is associated with body mass index and predisposes to childhood and adult obesity. Science 316 : 889-894 